\title{
Ă̆ır Vasıta Hava Kompresörü Arıza Durumlarının Naive Bayes Sınıflandırıcısı Kullanılarak Analizi
}

\author{
Emre Gül ${ }^{1 *}$, Mete Kalyoncu ${ }^{2}$ \\ 1*Yıldız Pul Otomotiv Motor Parçaları Sanayi A.Ş., Konya, Türkiye (ORCID: 0000-0003-0348-4904), emregl2816@gmail.com \\ ${ }^{2}$ Konya Teknik Üniversitesi, Mühendislik ve Doğa Bilimleri Fakültesi, Makine Mühendisliği Bölümü, Konya, Türkiye (ORCID: 0000-0002-2214-7631) \\ mkalyoncu@ktun.edu.tr
}

(İlk Geliş Tarihi 14 Ekim 2021 ve Kabul Tarihi 21 Aralık 2021)

(DOI: 10.31590 /ejosat.1009757)

ATIF/REFERENCE: Gül, E. \& Kalyoncu, M. (2021). Ağır Vasıta Hava Kompresörü Arıza Durumlarının Naive Bayes Sınıflandırıcısı ile Tahmini. Avrupa Bilim ve Teknoloji Dergisi, (31), 796-800.

$\ddot{O} \mathbf{z}$

Hava kompresörleri ağır vasıta fren sistemlerinin hava ile beslenmesi için hayati öneme sahiptir. İçerisinde bulundurduğu piston biyel mekanizması ile havanın istenilen basınca ulaştırılarak (10-12.5 bar) tanka depo edilmesini sağlamaktadır. Planlı bakımlarda bileşenlerinin cüzi ücretlerle değişimleri yapılabilirken, arıza durumlarında aracın yolda kalmasına sebep olabilmekte ve yüksek miktarda ücret ve plansız zaman kaybı ile onarımı yapılabilmektedir. Beklenmedik arıza süreleri ağır vasıtaların taşıdıkları ürünleri müşteriye geç teslim edilmesine sebep olabilmekte ve müşteri memnuniyetsizliğine sebep olmaktadır. Bu çalışma ile hava kompresöründe gerçekleşebilecek arıza durumları araştırılmış ve firma Ar-Ge biriminde oluşturulan test düzeneği ile belirlenen arızalar manuel olarak gerçekleştirilmiştir. Elde edilen veriler Dewesoft yazılımı ile kayıt altına alınmıştır. Python yazılımı kullanılarak Naive Bayes Sınıflandırıcısı modelleri oluşturulmuştur. Toplam 23.987 veri kullanılmıştır. Bu verilerin \%80’lik kısmı ile modeller eğitilmiş ve \%20 'lik kısmı ile arıza tahmininde bulunulmuştur. Sırasıyla eğitim ve test verisi hatalı tahmin sayıları; Bernoulli Naive Bayes Sınıflandırıcısı için 18062 - 4550, Multinominal Naive Bayes Sınıflandırıcısı için 16654 -4210, Gaussian Naive Bayes Sınıflandırıcısı için 961-258 veri hatalı tahminde bulunmuştur. Gaussian Naive Bayes sınıflandırıcısının bariz farkla doğru kararlar verdiği gözlemlenmiştir. Ayrıca sınıflandırma metrikleri incelenerek elde edilen sonuçlar değerlendirilmiştir.

Anahtar Kelimeler: Ağır Vasıta Hava Kompresörü Arızaları, Bernoulli - Multinominal - Gaussian Naive Bayes Sınıflandırıcısı, Makine Öğrenmesi

\section{Analysis of Heavy Vehicle Air Compressor Failure States Using Naive Bayes Classifier}

\begin{abstract}
Air compressors are vital for the air supply of heavy vehicle braking systems. With the piston connecting rod mechanism it has in it, it ensures that the air is delivered to the desired pressure (10-12.5 bar) and stored in the tank. While changes of its components can be made at small fees during planned maintenance, it can cause the vehicle to stay on the road in case of failure and can be repaired with a high amount of fees and unplanned loss of time. Unexpected failure times can cause heavy vehicles to deliver their products to the customer late and cause customer dissatisfaction. In this study, the fault situations that may occur in the air compressor were investigated and the deciencies determined by the test device created in the company's R \&D unit were performed manually. The obtained data were recorded with Dewesoft software. Naive Bayes Classifier models were created using Python software. A total of 23,987 data were used. Models were trained with $80 \%$ of the total data and fault prediction was made with $20 \%$. The training and test data, respectively, are incorrect prediction numbers; 18062-4550 for Bernoulli Naive Bayes Classifier, 16654-4210 for Multinomial Naive Bayes Classifier, 961-258 for Gaussian Naive Bayes Classifier data has been incorrectly estimated. It has been observed that the Gaussian Naive Bayes classifier makes correct decisions with obvious difference. In addition, the results obtained by examining the classification metrics were evaluated.
\end{abstract}

Keywords: Heavy Vehicle Air Compressor Fault, Bernoulli - Multinominal - Gaussian Naive Bayes Classifier, Machine Learning

* Sorumlu Yazar: emregl2816@gmail.com 


\section{Giriş}

Hava kompresörleri, içerisinde barındırdığı piston biyel mekanziması ile ortamdan aldığı havayı basınçlandırarak tanka depo edilmesini sağlamaktadır. Ağır vasıtalardaki ihtiyaç durumlarına göre tek veya çift silindirli olarak tasarlanmaktadır. Aracın hava ihtiyacına göre su ya da hava soğutmalı tipleri mevcuttur [1]. Şekil 1.' de ağır vasıta hava kompresörü resimleri gösterilmiştir.

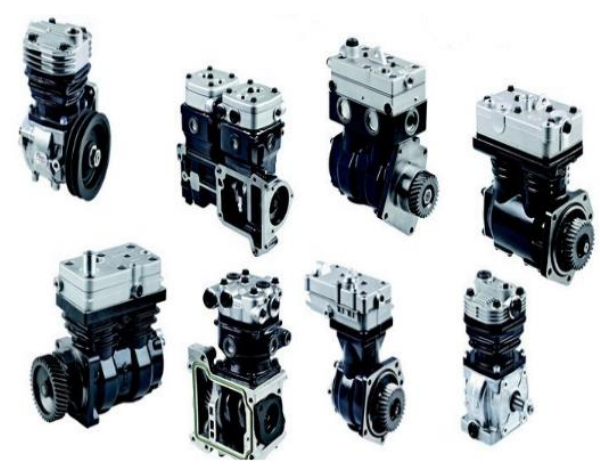

Şekil 1. Ağır Vasıta Hava Kompresörü [2]

Tır, traktör, otobüs ve kamyonlarda kullanılan pistonlu kompresörler 8-12,5 bar aralığında basınçlı hava üretmektedir. Ağır vasitalarda motor ağı ile kompresörün yağlanması sağlanmaktadır.

Kompresör ile ilgili literatür araştırmaları sonucunda bu bilgHava fren kompresörleri için gelişmiş sorun giderme kılavuzunda, fren sistemine giriş ve hava doldurma sistemi problemlerini teşhis etmek için testler içeren sorun giderme belirtileri anlatılmıştır [3]. Ticari araç sistemleri servis haberleri dokümanında ağır vasıta hava kompresörleri yăg verme sorununun sebep ve sonuçları incelenmiştir [4]. Almasi çalışmasında pistonlu kompresörlerin bileşen tasarımı ve üretimi, ticari noktalar, yardimc1 ve aksesuarlar, performans ve güvenilirlik ile ilgili optimum konfigürasyonunu makalesinde ele almıştır [5]. Bir internet sitesinde kompresörlerde arıza bulma başlığı altında pistonlu kompresör arızaları ve sebeplerinden bahsedilmiştir [6]. Endüstride kullanılan pistonlu kompresör arızaları ve sebeplerinden bahsedilmiştir internet sitesinde verilmiştir [7]. Prytz ve arkadaşları Volvo kamyonunda kayıtlı verileri kullanarak kompresör arızalarını tahmin etme konusundaki deneyimlerimi açıkladılar. VOLVO veri toplama işlemi için LVD isimli bir kayıtlı araç veri tabanı oluşturmuştur ve elde edilen veriler elektronik kontrol ünitelerinde saklanmaktadır ve tüm yerlerden gelen veriler bir merkezde toplanır. Veriler yetkili bir servise kablosuz olarak telematik bir ağ üzerinden gönderilir veya alınır. Verileri alırken sisteme düşen kamyonlardan 3 sınıfi baz aldılar; 1. kompresörü arıza vermemiş olanlar 2. kompresörü yeni arıza vermiş olanlar ve 3. olarak kompresör arızası verebilecek olanlar. Kompresör arızası olan 80 kamyon bunlara bağlı 10 LVD değeri seçtiler ve kompresörü arıza yapmamış 1440 kamyonu da sete eklediler. Bu çalışmanın en önemli sonucu olarak, Logged Vehicle Data (LVD) tabanlı veri madenciliğinin otomotiv endüstrisinde öngörücü bakım çözümü olarak kullanılmasının daha uygun bir yaklaşım olduğunu anlamak ve kestirimci bakımın mümkün olduğunu ve göreceli olarak düşük miktarda veri olmasına rağmen önemli maliyet tasarrufları ile sonuçlanabileceğini göstermeye çalıştılar [8].
Townsend ve Badar çalışmalarında pistonlu kompresörlerin çalışmasına ilişkin arıza verileri, sürekli basınç izleme sistemlerinin güvenilirliği, etkinliği ve ekonomik analizini gerçekleştirmek için toplandı. Amaçları sürekli basınç izlemenin güvenilirliğini, verimliliğini ve mühendislik ekonomisini incelemektir. Sonuç olarak sürekli basınç izleme teknolojisinin kompresör filosunun verimliliği üzerinde güçlü bir etkiye sahip olduğunu gösterdiler [9].

Aydıner ve ark. 2019 yılında gerçekleştirdikleri çalışmada ana sanayi üretimi hava kompresörünün performans testlerini test cihazında gerçekleştirmiş ve ana sanayinin yayınladığı kompresör performans verileri ile kıyaslamasını yapmışlardır. Bu sayede test düzeneğinin doğrulaması yapılmıştır [10]. Gül ve arkadaşlarnın 2019 yılında yaptıkları çalışmada ise yaygın görülen hava kompresörü arızalarından bahsedilmiş ve performans değerleri aynı test düzeneğinde belirlenmiştir [11]. 2020 yılında yapmış oldukları çalışmada ise arıza verilerinin bir kısmı ile ağır vasıta hava kompresörü piston segmanı aşınması durumlarında K-en yakın komşu algoritması sınıflandırma performansı [12] ile rastgele orman algoritması arıza tahmin durumlarını incelenmiştir [13].

Yapılan araştırmalar ve teknik servis görüşmeleri neticesinde hava kompresörlerinde yaklaşık 80'e yakın arıza tespit edilmiştir. $\mathrm{Bu}$ çalışmada kompresör ve bağlantılı olduğu mekanizmaların bakımlarının yapılmaması sebebiyle kompresörde görülen en yaygın arızalar üzerinde durulmuştur.

2019 yılında en s1k görülen kullanıcı kaynaklı arıza kaydı (620 adet) verileri incelenerek Şekil 2.'de grafik dağılımları paylaşı1mıştır.

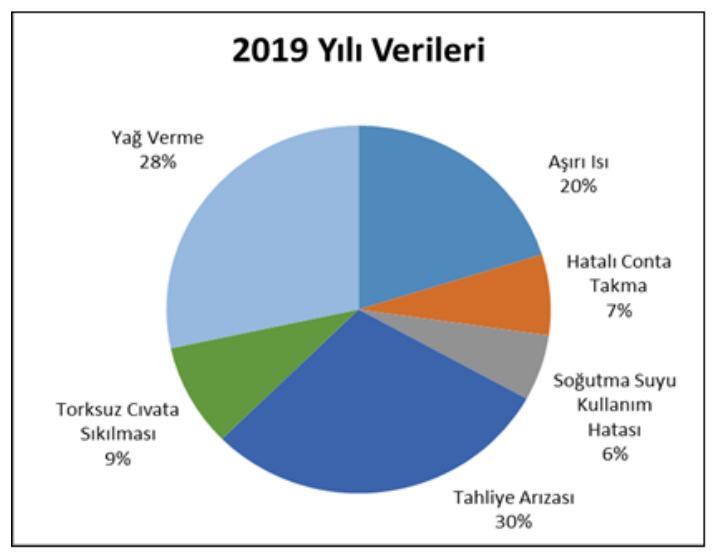

Şekil 2. Çeşitli Markalara Ait Teknik Servis 2018 Yılı Verileri

Kompresörün hava girişinden toz partiküllerini alması sonucu silindir gömleği ile piston segmanları arasında aşınma oluşur. Bu aşınma gömlek yüzeyinde üst ölü noktada $0.1 \mathrm{~mm}$ iken, alt ölü noktada $0.05 \mathrm{~mm}$ aralığında değişmektedir. Piston segmanlarında ise segman kalınlığı $3 \mathrm{~mm}$ 'den $2.30 \mathrm{~mm}$ ölçülere kadar inebilmektedir. Piston segmanları ile silindir gömleği arasında oluşan boşluk, kompresörün kartere hava kaçırmasına ve karterdeki yağın hava çıkışından tanka doğru ilerlemesine yani yağ vermeye (taşınıma) sebep olmaktadır. Fazla yağ, hava kurutucu tahliye valfinin arıza göstermesine sebep olabilir. Hava kurutucu tahliye valfinde oluşan arıza tanka yağ kaçmasına ve sistemin yağlanmasına sebep olabilirken, bozulan tahliye hava kompresörünün sürekli yüke girip çıkmasına sebep olabilmektedir. 
Tahliye arızasının alt başlıkları; hava girişinin tıkalı olması, hava çıkışının tıkalı olması, hava giriş ve çıkışının tıkalı olması, sürekli yükte çalışma arızaları olarak sıralanabilmektedir.

Motor hava filtresinden filtrelenerek geçen havanın bir bölümü motora gönderilirken, kalan kısmı kompresöre gönderilmektedir. Hava filtresinin tıkalı olması ya da borulardaki tıkanıklık motor girişinde vakuma sebep olabilmekte, kompresörde tank dolum süresini artırmakta ve hava çıkış hattına yağ vermesinde potansiyel bir artışa sebep olabilmektedir. Kompresör hava çıkışının tıkalı olması hava sisteminin yavaş doldurulmasına, kompresörün sürekli yükte çalışmasına, hava kompresörünün aşırı 1sınması ve daha fazla yağ vermesine sebep olabilmektedir. Bununla birlikte araçtaki yağın kirli olması içerisinde toz partiküllerini bulundurması hava kompresöründe erken aşınmalara yol açarak yağ vermeye sebep olabilmektedir [14].

Sürekli yükte çalışma durumu sonucunda kompresör sürekli yüke girip çıkarken sıcaklığın artışına sebep olarak, kompresör içerisinde yağ buharının segmanları geçerek kompresör çıkışında kurum oluşumuna sebep olabilmektedir. Kompresör çıkışında oluşan kurum çıkış hattını tıkayarak tankın dolum süresini artırabilmektedir. Ayrıca basınçların düzensiz olması kompresör pleytine bağlı by-pass mekanizmasının sürekli devreye girip çıkmasıyla aşınmasına buna bağlı olarak mekanizmanın açık kalması ve kompresörün tankta hava doldurmaması gibi sorunlara yol açtığı gözlemlenebilmektedir.

Aşırı 1S1 arızasının birçok sebebi olabilmektedir. Kompresörler \%25 oranında yükte çalışacak şekilde tasarlanırlar. $\mathrm{Bu}$ çalışma performansı kompresörlerin ömür ve dayanım sürelerinin maksimumda olması açısından önem arz etmektedir. Kompresörün sürekli yükte olması veya sürekli yüke girip çıkması, soğutma suyu sıcaklığının uzun süreli çalışma anında $120^{\circ} \mathrm{C}$ sıcak ve üzerinde olması, soğutma suyu debisinde düşüş, hatalı soğutma suyu kullanımı gibi sebeplerden dolayı kompresör kapağında aşırı 1sı oluşumu beklenir. Kompresör kapağı ile pleyti arasındaki NBR contaların fiziksel özelliklerini kaybetmesine ve bunun sonucunda suya hava kaçırma, tankta hava doldurmama, atmosfere hava salınımı gibi problemlerin oluşmasında etkilidirler. Şekil 3.'de NBR conta paylaşılmıştır.

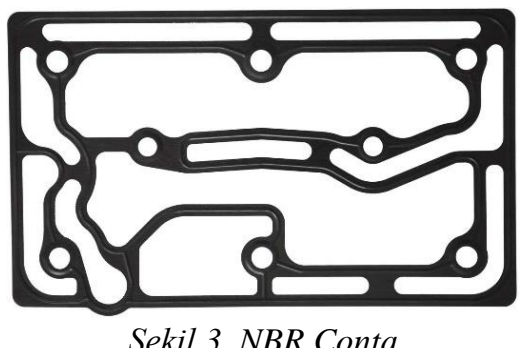

Şekil 3. NBR Conta

\subsection{Naive Bayes Sinıflandırıcısı}

Koşullu olasılık temeline dayanarak özniteliklerinin tümünün sınıflandırılmasında, birbiri arasında eşit ve bağımsız olduğu varsayılan koşullu olasılık temellerine dayanan basit yapılı bir sınıflandırmadır. Sınıflandırma işlemi farklı özniteliklerin sonuca olan etkisinin birleşmesiyle yapılır [15].

Naive Bayes istatistiksel yöntemler kullanarak sınıflandırma yapmaktadır ve performans açısından önemli bir algoritmadır. Niteliklerin öneminin hepsinde aynı derecede olduğu kabul edilir
[16]. Naive Bayes Algoritmasının matematiksel formülü $\mathrm{P}(\mathrm{Cj} \mid \mathrm{x})$ eşitliğinde verilmiştir.

- $\quad p(x \mid C j)$ : Sınıf jeeden bir örneğin x olma olasılığı

- $\quad P(C j)$ : Sınıf jeenin ilk olasılığı

- $\quad \mathrm{p}(\mathrm{x})$ : Herhangi bir örneğin $\mathrm{x}$ olma olasılığ

- $\quad \mathrm{P}(\mathrm{Cj} \mid \mathrm{x})$ : $\mathrm{x}$ olan bir örneğin sınıf j jeen olma olasılığ (son olasilik)

$P\left(C_{j} \mid x\right)=\frac{p\left(x \mid C_{j}\right) P\left(C_{j}\right)}{p(x)}=\frac{p\left(x \mid C_{j}\right) P\left(C_{j}\right)}{\sum_{k} p\left(x \mid C_{k}\right) P\left(C_{k}\right)}$

Naive Bayes sınıflandırıcısı Bernoulli Naive Bayes, Multinominal Naive Bayes ve Gaussian Naive Bayes olarak 3 başlikta incelenebilir.

\section{Materyal ve Metot}

Firma bünyesinde ağır vasıta hava kompresörünün ömür testlerinin gerçekleştirilebilmesi için oluşturulan test düzeneğine ait şema Şekil 4.'de verilmiştir.

Veri toplama ve kayıt yazılımı olarak Dewesoft kontrolcüsü ve Dewesoft x3 yazılımı kullanılmıştır. Kompresör ve bağlantı hattı üzerine yerleştirilen sensörler vasıtasıyla elde edilen veriler sayesinde sistemin kontrolü de dewesoft ile sağlanmıştır. Kayıt altına alınan veriler yazılım ile Excel formatına dönüştürüldükten sonra etiket değerleri eklenerek, Python programının okuyabileceği csv. formatında kayıt edilmiştir [17].

Kompresörün araç üzerinde çalışmasının simule edilebilmesi için oluşturulan test cihazında kompresör ön kısmından flanş üzerine montajlanmıştır. Elektrik motorundan tahrik alabilmesi için araya kaplin bağlantısı yapılarak kompresördeki olumsuzluk durumlarında sistemin arıza görmesi engellenmiştir.

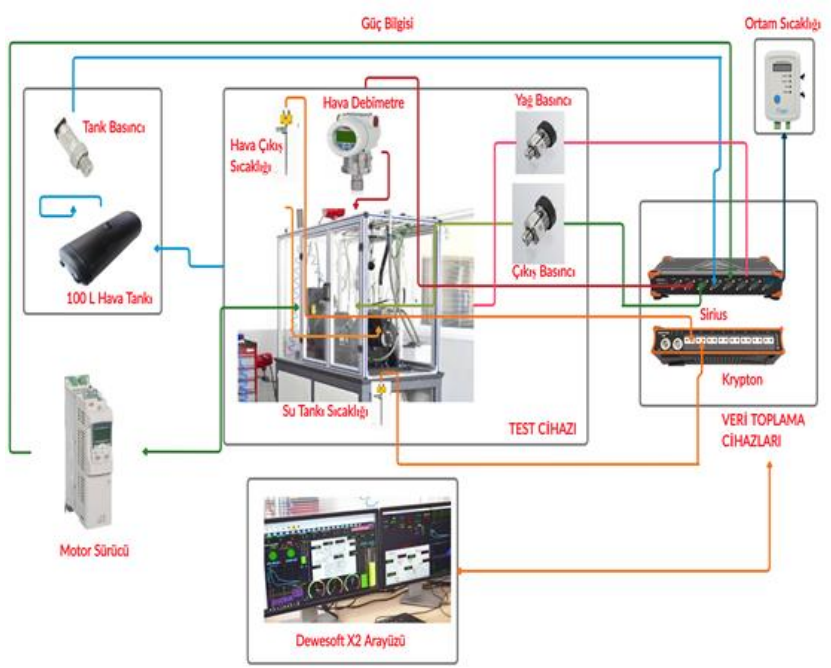

Şekil 4. Hava Kompresörü Uzun Ömür Test Düzeneği

(Yıldız Pul Otomotiv Motor Parçaları Sanayi A.Ş.)

Hava kompresörü test düzeneğinde sistemsel olarak yaklaşık 40 kanaldan aynı anda senkron bir şekilde veri alınması mümkün olabilmektedir. 
Test cihazında kullanılan sensör listesi Çizelge 1.'de verilmiştir.

Çizelge 1. Bă̆lantı Konumlarına Göre Kullanılan Sensörler

\begin{tabular}{|c|c|c|c|}
\hline No & Ölçüm Tipi & Ölçüm Metodu & Birimi \\
\hline 1 & Tank Basıncı & Basınç Sensörü & bar \\
\hline 2 & Yağ Basıncı & Basınç Sensörü & bar \\
\hline 3 & Çıkıș Hava Basıncı & Basınç Sensörü & bar \\
\hline 4 & Hava Debisi & Debimetre & $\mathrm{Kg} / \mathrm{h}$ \\
\hline 5 & Güç Tüketimi & Motor Sürücüsü & $\mathrm{kW}$ \\
\hline 6 & Ortam Sicaklığ & Sicaklık Sensörü & ${ }^{\circ} \mathrm{C}$ \\
\hline 7 & Giriş Su Sicaklığ & Sıcaklık Sensörü & ${ }^{\circ} \mathrm{C}$ \\
\hline 8 & $\begin{array}{c}\text { Çıkış Hava Sıcaklığı } \\
\text { (İlk) }\end{array}$ & Sicaklık Sensörü & ${ }^{\circ} \mathrm{C}$ \\
\hline 9 & $\begin{array}{l}\text { Çıkış Hava Sıcaklığı } \\
\text { (Son) }\end{array}$ & Sicaklık Sensörü & ${ }^{\circ} \mathrm{C}$ \\
\hline 10 & Motor Devri & Motor Sürücüsü & rpm \\
\hline 11 & Giriş Su Debisi & Debimetre & $1 / \mathrm{d}$ \\
\hline
\end{tabular}

Giriş verilerine karşın, çıkış verisi olarak kompresör çalışma durumları etiketlenmiştir. 18 farklı durumun her biri için, 11 farklı sensörden veriler kompresör çalışma anında kayıt altına alınmıştır. Tank basıncının 8 bar' dan 12.5 bar seviyelerine gelenekadar saniyede 2 veri kayıt altına alınmış ve toplamda 23.987 veri algoritmaların eğitimi ve test edilmesi için kullanılmıştır.

Tablo 1.' de normal çalışma ve arızalı çalışma durumlarının etiketlendiği değerler gösterilmiştir.

Tablo 1. Arıza Durumlarına Bağlı Etiketli Verilerin Gösterimi

\begin{tabular}{l|c}
\hline \multicolumn{2}{c}{ Giriş Parametrelerine Etiketlenmiş Çıkış Parametreleri } \\
\hline Normal Koşullarda Çalışma Durumu & 0 \\
\hline Hava Girişinin Tıkalı Olması Durumu & $1: 2: 3: 4$ \\
\hline Hava Çıkışının Tıkalı Olması Durumu & $5: 6: 7$ \\
\hline Hava Girişi ve Çıkışının Tıkalı Olması Durumu & $8: 9: 10: 11$ \\
\hline Aşırı Isı Durumu & $12: 13: 14$ \\
\hline $\begin{array}{l}\text { Tahliye Arızası Durumu (\%40 Sürekli Yükte } \\
\text { Çalışma) }\end{array}$ & 15 \\
\hline Yağ Verme (Taşınım) Durumu & $16: 17: 18$ \\
\hline
\end{tabular}

Yapılan testlerde önemli olan parametrelerin varlığıdır. Hava kompresörlerinde giriş parametrelerine karşın 2 çıkış parametresi (Debi miktar1-Güç tüketimi) vardır. OEM üreticileri tarafından paylaştıkları teknik resimlerde kompresörlerinin çalışma performansını gösterebilmek için debi miktarı-güç tüketimi grafiklerini, her çalışma hızına (600-3000d/d) göre test ederek kullanıcılarına sunmaktadır. Arıza durumlarında giriş ve çıkış parametrelerinde küçükte olsa bir değişim söz konusu olacaktır. Bu değişimler sensörler vasıtasıyla ölçülerek sayısal büyüklüklere dönüştürülür.

\section{Araştırma Sonuçları ve Tartışma}

Naive Bayes Sınıflandırıcısı için Bernoulli Naive Bayes Sinıflandırıcıs1, Multinominal Naive Bayes Sinıflandırıcısı, Gaussian Naive Bayes Sınıflandırıcısı olmak üzere üç farklı tipte eğitim gerçekleştirilmiştir.

Tablo 2.'de Naive Bayes sınıflandırma yöntemlerinin eğitim verileri üzerindeki sınıflandırma performansları gösterilmiştir.
Tablo 3.'de Naive Bayes sınıflandırma yöntemlerinin test verileri üzerindeki sınıflandırma performansları gösterilmiştir.

Tablo 2. Makine Öğrenmesi Yöntemlerinin Sınıflandırma Performanslarl (Ĕgitim Veri Seti)

\begin{tabular}{c|l|l|l|l|l|l}
\hline \multicolumn{1}{c|}{ Tip } & $\begin{array}{c}\text { Doğruluk } \\
(\%)\end{array}$ & Kesinlik & Duyarlılık & $\begin{array}{c}\text { F1 }_{\text {Skoru }} \\
\text { Sappa } \\
\text { değeri }\end{array}$ & $\begin{array}{c}\text { Tahmin } \\
\text { Edilen } \\
\text { Veri } \\
\text { Sayı1 }\end{array}$ \\
\hline $\begin{array}{l}\text { Bernoulli Naive } \\
\text { Bayes } \\
\text { Sinıflandırıcıs1 }\end{array}$ & $\% 5.90$ & 0.00 & 0.06 & 0.01 & 0.00 & 18062 \\
\hline $\begin{array}{l}\text { Multinominal } \\
\text { Naive Bayes } \\
\text { Sinıflandırıcıs1 }\end{array}$ & $\% 13.20$ & 0.23 & 0.13 & 0.12 & 0.08 & 16654 \\
\hline $\begin{array}{l}\text { Gaussian Naive } \\
\text { Bayes } \\
\text { Sinıflandırıcıs1 }\end{array}$ & $\% 95$ & 0.96 & 0.95 & 0.95 & 0.95 & 961 \\
\hline
\end{tabular}

Tablo 3. Makine Öğrenmesi Yöntemlerinin Sınıflandırma Performanslarl (Test Veri Seti)

\begin{tabular}{|c|c|c|c|c|c|c|}
\hline Tip & $\begin{array}{l}\text { Doğruluk } \\
(\%)\end{array}$ & Kesinlik & Duyarlılık & $\begin{array}{c}\mathrm{F}_{1} \\
\text { Skoru }\end{array}$ & $\begin{array}{l}\text { Kappa } \\
\text { değeri }\end{array}$ & $\begin{array}{c}\text { Hatalı } \\
\text { Tahmin } \\
\text { Edilen } \\
\text { Veri } \\
\text { Sayısı }\end{array}$ \\
\hline $\begin{array}{l}\text { Bernoulli } \\
\text { Naive Bayes } \\
\text { Sinıflandırıcısı }\end{array}$ & $\% 5.20$ & 0.00 & 0.05 & 0.01 & 0.00 & 4550 \\
\hline $\begin{array}{l}\text { Multinominal } \\
\text { Naive Bayes } \\
\text { Sınıflandırıcısı }\end{array}$ & $\% 12.30$ & 0.23 & 0.12 & 0.11 & 0.07 & 4210 \\
\hline $\begin{array}{l}\text { Gaussian } \\
\text { Naive Bayes } \\
\text { Sinıflandırıcısı }\end{array}$ & $\% 94.60$ & 0.96 & 0.95 & 0.95 & 0.94 & 258 \\
\hline
\end{tabular}

\section{Sonuç ve Öneriler}

Çalışmada ağır vasıta hava kompresörü arızaları sınıflandırılarak test düzeneği vasıtasıyla belirlenen arızalar manuel olarak meydana getirilmiş ve verileri kayıt altına alınmıştır. Kayıt altına alınan veriler belirlenen makine öğrenmesi algoritma modellerinin oluşturulmasında kullanılmış ve $10 \mathrm{~kat}$ çapraz doğrulama yöntemi ile modellerin genelleştirilmesi sağlanmış başarı oranlarının artırılması hedeflenmiştir. Elde edilen algoritma modellerinin performans değerlendirme sonuçlarına ulaşabilmek için doğruluk (accuracy), Kappa değeri, kesinlik (precision), duyarlılık (recall), F1 skoru gibi metriklere bakılmıştır.

Bernoulli, Multinominal, Gaussian olmak üzere üç farklı çözüm yaptırılmıştır. Gaussian Naive Bayes sınıflandırıcısının bariz farkla doğru kararlar verdiği gözlemlenmiştir. 
Etiket değeri bilinen algoritmaların hiç görmediği veriler, algotimalara tanıtılarak tahminde bulunması sağlanmış ve 18 farklı etiket değeri için verilen verilerde;

> Bernoulli Naive Bayes Sınıflandırıcısı Tahmin Matrisi incelendiğinde tüm çalışma durumlarına ait veriler $\% 5.89$ oranla 18 numaralı çalışma durumu sınıfina dahil edilmiştir. Algoritmanın başarılı bir sonuç vermediği gözlemlenmiştir.

$>$ Multinominal Naive Bayes Sinıflandırıcısı Tahmin Matrisi incelendiğinde 4, 9, 14, 18 numaralı çalışma durumları doğru tahmin edilmiştir. Ancak oran olarak bakıldığında çok düşük oranlarla doğru tahmin söz konusudur. Algoritmanın başarılı bir sonuç vermediği gözlemlenmiştir.

$>$ Gaussian Naive Bayes Sinıflandırıcısı Tahmin Matrisi incelendiğinde $1,4,5,6,8,11,12,15,17$ numaralı çalışma durumlarının yanlış tahmin edildiği görülmüştür. Diğer sınıflara ait verilerin yüksek oranla doğru tahmin edildiği gözlemlenmiştir.

Aktif çalışan sistemlerin zamanla bakımsız bırakılması ya da plansız bakım periyotları maddi ve iş gücü zamanında kayıplara yol açmaktadır. Sistemlerde arıza göstergesi olabilecek durumların yaşanmaması bakımların ileri tarihlere ertelenmesine sebep olurken sistemin hangi bölgesinde arıanın gerçekleşebileceğini bilmek zaman ve maddi açıdan kullanıcıları memnun etmektedir. Bakım zamanının bilinebilmesi ya da o durumun yaşanabileceğinin öncesinden bilinmesi, kullanıcıların planlı davranış sergilemesi ve işlerin zamanında çözülmesi bakımından önem arz etmektedir.

Ağır vasıta hava kompresörü verileri için sürekli veri alma yöntemi ile Naive Bayes Sınıflandırıcı yöntemlerinin başarı oranları görülmektedir. Bu çalışma mekanik makinelerin çalışma anındaki durumlarının incelenmesi için örnek teşkil etmekte ve hava kompresörü arızalarının tahmin edilmesinde makine öğrenmesi algoritmalarının etkili sonuçlar verebildiğini göstermektedir.

\section{Teşekkür}

$\mathrm{Bu}$ çalışmanın gerçekleşmesinde verdikleri destekten dolayı Yıldız Pul Otomotiv Motor Parçaları Sanayi AŞ. firması ve ArGe Merkezi çalışma arkadaşlarımıza teşekkür ederiz.

\section{Kaynakça}

[1]Ünüvar, E., Gül, E., Aydıner, M. Ş. ve Kalyoncu, M., 2019, Investigation of the effect of intake and exhaust valve dimensions on performance for heavy duty vehicle air compressors, The International Aluminium-Themed Engineering and Natural Sciences Conference "IATENS2019" Seydişehir / Konya, 1-1118.

[2]Anonymous, 2019a, Heavy vehicle air compressor pictures, https://moto-press.pl/en/vaden-original.html [Ziyaret Tarihi: 10.06.2020].

[3]Bendix, 2004, Advanced troubleshooting guide for air brake compressors: 1-24.

[4]Bremse, K., 2007, Kompresör yağ taşınımı. Servis Haberleri, Knorr-Bremse Ticari Araç Sistemleri, 1-14.

[5]Almasi, A., 2009, Reciprocating compressor optimum design and manufacturing with respect to performance, reliability and cost, World Academy of Science, Engineering Technology, 52, 48-53.

[6]Servis, R., 2010, Kompresörlerde arıza bulma, http:/rittalservisi. blogspot.com/ 2010/11/bolum-2kompresorlerde-ariza-bulma.html, [Ziyaret Tarihi : 4 Kasım 2019].

[7]Kompresör,Ü., 2012, Kompresör arızaları, http://www. unalankompresor .com/ kompresor_arizalari.html, [Ziyaret Tarihi : 4 Kasim 2019].

[8]Prytz, R., Nowaczyk, S., Rögnvaldsson, T. ve Byttner, S., 2013, Analysis of truck compressor failures based on logged vehicle data, 9th International Conference on Data Mining, Las Vegas, Nevada, USA, July 22-25, 2013.

[9]Townsend, J. ve Badar, M. A., 2018, Impact of condition monitoring on reciprocating compressor efficiency, Journal of Quality in Maintenance Engineering.

[10]Aydıner, M. Ş., Ünüvar, E., \& Kalyoncu, M. Bir Ağır Vasıta Hava Kompresörünün Performansının Deneysel olarak Incelenmesi, International Symposium on Automotive Science and Technology, ISASTECH, 2019.

[11]Gül, E., Ünüvar, E., \& Kalyoncu, M. Ağır Vasıta Hava Kompresörü Arızaları ve Performansa Etkilerinin Deneysel Incelenmesi. Paper presented at the International Symposium on Automotive Science and Technology, 2019.

[12]Gül, E , Kalyoncu, M . Ağır Vasıta Hava Kompresörü Piston Segmanı Aşınması Durumlarında K-En Yakın Komşu Algoritmasının Sınıflandırma Performansının İncelenmesi. Avrupa Bilim ve Teknoloji Dergisi, 2020, 78-90 . DOI: 10.31590/ejosat.802958.

[13]Gül, E., Kalyoncu, M., Kula, G., 2020, “Ağır vasıta hava kompresorlerinde piston segmanlarından yağ verme problemlerinin rastgele orman algoritmasi ile tahmini", The International Conference of Materials and Engineering Technology, Gaziantep.

[14]Bremse, K., 2008, Health for your air compressor, Service Instructions, Knorr-Bremse 1-2.

[15]Cömert, B., 2016, Alın bölgesinden alınan elektrookülogram (EOG) işaretleri için ölçüm devresi tasarımı ve sınıflandırılması, Balıkesir Üniversitesi, Fen Bilimleri Enstitüsü, 97.

[16]Aydın, D. B., 2016, Yenidoğan yoğun bakım ünitesinde idrar yolu enfeksiyonunu tanımlama için yapay sinir ağı tabanlı bir karar destek sisteminin geliştirilmesi Bozok Üniversitesi Fen Bilimleri Enstitüsü 67.

[17]Gül, E., Ağır Vasıta Hava Kompresörü Arızalarının Makine Öğrenmesi Yöntemleri Kullanılarak Analizi, Yüksek Lisans Tezi, Konya Teknik Üniversitesi, Lisansüstü Eğitim Enstitüsü, Makine Mühendisliği Anabilim Dalı, 2020. 